\title{
Environmental epidemiology in Norway
}

\author{
Bert Brunekreef \\ Institute for Risk Assessment Sciences, Universiteit Utrecht \\ Institute for Risk Assessment Sciences, Universiteit Utrecht, PO Box 80176, 3508 TD, Utrecht, Netherlands \\ Telephone 31302535400 direct line $31302539490 \quad$ Telefax 31302539499 e-mail b.brunekreef@iras.uu.nl
}

I am from the most densely populated country in Europe (393 inhabitants per square kilometer, not counting ministates such as Vatican city). Norway's population density is just about the lowest at 14 per square kilometer. As environmental pressures and problems are closely related to population density, one would expect the Netherlands to devote rather more resources to studying environmental health problems than Norway. Yet, judging from research output as evident from MEDLINE, this is not so. The simple (one could argue: simplistic) search string 'environmental epidemiology Norway' produces 54 publications per 1 million inhabitants. The score for the Netherlands is just 25.

Now, a perhaps large part of the explanation lies in regional traditions in epidemiology. Scandinavia has long been strong on epidemiologic research, and the three other countries Sweden, Denmark and Finland produced even more papers in this field per million inhabitants (64-85). But another long-term stronghold in epidemiology, the U.K., is about level with the Netherlands at 27 per million, and Switzerland, Germany, Spain, Italy, Belgium and France bottom out at 8-16 per million. Excellent population health registries existing in Scandinavian countries have stimulated epidemiologic research into many issues including environmental health risks exemplified by studies of the effects of Chernobyl-disaster related radioactive fall-out on birth defects in Norway ${ }^{1-3}$.

Whereas population density drives some environmental exposures (such as those related to traffic, energy production), it is essentially unrelated to others. We all live in homes, and the home indoor environment can be a source of many contaminants from tobacco smoke, cooking, moisture, home decoration etc. Such exposures are of concern everywhere. Norwegian researchers have addressed a variety of indoor pollution issues, including indoor surface materials ${ }^{4,5}$, indoor exposure to tobacco smoke, nitrogen dioxide, allergens and dampness and mold problems ${ }^{6-10}$. Water purification is also a process unrelated to population density, and Norwegian epidemiologists have contributed to our understanding of the possible ill effects of chlorination by-products on, e.g., birth defects and foetal growth ${ }^{11-13}$. The use of child day care facilities has been widespread in Scandinavia for decades, and day care visits have been linked to acute otitis media and respitory infections in various Norwegian studies $^{14-18}$.
Yet other exposures may be of specific concern because of geochemistry or local dietary habits. An example of the former category is radon gas that is high in areas of Norway and Sweden because the soil or bedrock on which homes have been build is rich in uranium $^{19-21}$. An example of the latter is elevated exposure to persistent contaminants accumulated in fish in frequent fish consumers living in coastal areas ${ }^{22}$. Fish consumption may, on the other hand, be protective against development of allergic and heart disease $\mathrm{e}^{23}$. The cold winter climate has stimulated experimental as well as epidemiological research into the effects of cold temperatures on human health ${ }^{24,25}$.

But even the study of environmental exposures at the low end of the international range of exposure variation can be surprisingly fruitful. Nowadays, there is a lot of debate about whether thresholds exist at the population level for non-cancer effects of air pollution. To study this, one needs low exposure areas, not high exposure areas. Obviously, within the low exposure areas there needs to be sufficient contrast in exposure to allow meaningful studies, but new advanced approaches to assessing exposure to air pollution at the microscale have made such studies possible, for example in Oslo where exposure contrasts are also enhanced because of the topography ${ }^{26-28}$. Time series studies on day-to-day variations in respiratory hospital admissions in relation to low levels of traffic-related air pollutants have also been conducted, suggesting a specific role of pollutants other than PM10 ${ }^{29,30}$. Another exposure of much current interest, UV radiation possibly increased by a diminishing stratospheric ozone layer, has also been fruitfully investigated in Norway where in view of the high latitude, UV exposure is less than in more southern countries ${ }^{31}$.

Also, heavy industry and associated pollution just across the Norwegian-Russian border has created rare opportunities to search for clues in the aetiology and exacerbation of allergic disease $e^{32,33}$ as well as cancer and heart disease $\mathrm{e}^{34}$; another site polluted by industrial emissions in Norway has also been investigated to elucidate effects or air pollution on bronchial responsiveness in children ${ }^{35}$; historic nuclear testing across the Russian border has initated studies into thyroid cancer $^{36}$.

In conclusion, despite its relatively small population, and its lack of environmental health problems typically associated with high population density, Norwegian researchers have been remarkably productive 
in the field of environmental epidemiology in the past decades. The strong infrastructure in terms of population health registries provides a basis for continued productive research in this area. Inclusion of novel exposure assessment modeling tools within geographic information systems will provide additional opportunities for research by linking geocoded health and exposure data.

\section{REFERANCES}

1. Lie RT. Environmental epidemiology at the Medical Birth Registry of Norway; strengths and limitations. Cent Eur J Public Health 1997; 5 (2): 57-9.

2. Lie RT, Irgens LM, Skjaerven R, Reitan JB, Strand P, Strand T. Birth defects in Norway by levels of external and food-based exposure to radiation from Chernobyl. Am J Epidemiol 1992; 136 (4): 377-88.

3. Lie RT, Wilcox AJ, Skjaerven R. A population-based study of the risk of recurrence of birth defects. $N$ Engl J Med 1994; 331 (1): 1-4.

4. Jaakkola JJ, Verkasalo PK, Jaakkola N. Plastic wall materials in the home and respiratory health in young children. Am J Public Health 2000; 90 (5): 797-9.

5. Jaakkola JJ, Oie L, Nafstad P, Botten G, Samuelsen SO, Magnus P. Interior surface materials in the home and the development of bronchial obstruction in young children in Oslo, Norway. Am J Public Health $1999 ; 89$ (2): 188-92.

6. Forsberg B, Pekkanen J, Clench-Aas J, Martensson MB, Stjernberg N, Bartonova A, Timonen KL, Skerfving S. Childhood asthma in four regions in Scandinavia: risk factors and avoidance effects. Int J Epidemiol 1997; 26 (3): 610-9.

7. Lodrup Carlsen KC. The environment and childhood asthma (ECA) study in Oslo: ECA-1 and ECA-2. Pediatr Allergy Immunol 2002; 13 Suppl 15: 29-31.

8. Magnus P, Nafstad P, Oie L, Carlsen KC, Becher G, Kongerud J, Carlsen KH, Samuelsen SO, Botten G, Bakketeig LS. Exposure to nitrogen dioxide and the occurrence of bronchial obstruction in children below 2 years. Int J Epidemiol 1998; 27 (6): 995-9.

9. Lodrup Carlsen KC, Carlsen KH, Nafstad P, Bakketeig L. Perinatal risk factors for recurrent wheeze in early life. Pediatr Allergy Immunol 1999; 10 (2): 89-95.

10. Lodrup Carlsen KC, Jaakkola JJ, Nafstad P, Carlsen KH. In utero exposure to cigarette smoking influences lung function at birth. Eur Respir J 1997; 10 (8): 1774-9.

11. Hwang BF, Magnus P, Jaakkola JJ. Risk of specific birth defects in relation to chlorination and the amount of natural organic matter in the water supply. Am J Epidemiol 2002; 156 (4): 374-82.

12. Jaakkola JJ, Magnus P, Skrondal A, Hwang BF, Becher G, Dybing E. Foetal growth and duration of gestation relative to water chlorination. Occup Environ Med 2001; 58 (7): 437-42.

13. Magnus P, Jaakkola JJ, Skrondal A, Alexander J, Becher G, Krogh T, Dybing E. Water chlorination and birth defects. Epidemiology 1999; 10 (5): 513-7.

14. Kvaerner KJ, Nafstad P, Hagen J, Mair IW, Jaakkola JJ. Early acute otitis media: determined by exposure to respiratory pathogens. Acta Otolaryngol Suppl 1997; 529: 14-8.

15. Kvaerner KJ, Nafstad P, Jaakkola JJ. Upper respiratory morbidity in preschool children: a cross-sectional study. Arch Otolaryngol Head Neck Surg 2000; 126 (10): 1201-6.

16. Nafstad P, Hagen JA, Botten G, Jaakkola JJ. Lower respiratory tract infections among Norwegian infants with siblings in day care. Am J Public Health 1996; 86 (10): 1456-9.

17. Nafstad P, Hagen JA, Oie L, Magnus P, Jaakkola JJ. Day care centers and respiratory health. Pediatrics 1999; 103 (4 Pt 1): 753-8.

18. Nafstad P, Magnus P, Jaakkola JJ. Early respiratory infections and childhood asthma. Pediatrics $2000 ; 106$ (3): E38.

19. Magnus K, Engeland A, Green BM, Haldorsen T, Muirhead CR, Strand T. Residential radon exposure and lung cancer - an epidemiological study of Norwegian municipalities. Int J Cancer 1994; 58 (1): 1-7.

20. Stigum H, Strand T, Magnus P. Should radon be reduced in homes? A cost-effect analysis. Health Phys 2003; 84 (2): $227-35$.

21. Stranden E. Radon in Norwegian dwellings and the feasibility of epidemiological studies. Radiat Environ Biophys 1986; 25 (1): 37-42.

22. Furberg AS, Sandanger T, Thune I, Burkow IC, Lund E. Fish consumption and plasma levels of organochlorines in a female population in Northern Norway. J Environ Monit 2002; 4 (1): 175-81.

23. Nafstad P, Nystad W, Magnus P, Jaakkola JJ. Asthma and allergic rhinitis at 4 years of age in relation to fish consumption in infancy. J Asthma 2003; 40 (4): 343-8. 
24. Nafstad P, Skrondal A, Bjertness E. Mortality and temperature in Oslo, Norway, 1990-1995. Eur J Epidemiol 2001; 17 (7): 621-7.

25. Mercer JB, Osterud B, Tveita T. The effect of short-term cold exposure on risk factors for cardiovascular disease. Thromb Res 1999; 95 (2): 93-104.

26. Nafstad P, Haheim LL, Oftedal B, Gram F, Holme I, Hjermann I, Leren P. Lung cancer and air pollution: a 27 year follow up of 16209 Norwegian men. Thorax 2003; 58 (12): 1071-6.

27. Nafstad P, Haheim LL, Wisloff T, Gram F, Oftedal B, Holme I, Hjermann I, Leren P. Urban air pollution and mortality in a cohort of Norwegian men. Environ Health Perspect 2004; 112 (5): 610-5.

28. Gram F, Nafstad P, Haheim LL. Estimating residential air pollution exposure among citizens in Oslo 19741998 using a geographical information system. J Environ Monit 2003; 5 (4): 541-6.

29. Hagen JA, Nafstad P, Skrondal A, Bjorkly S, Magnus P. Associations between outdoor air pollutants and hospitalization for respiratory diseases. Epidemiology 2000; 11 (2): 136-40.

30. Oftedal B, Nafstad P, Magnus P, Bjorkly S, Skrondal A. Traffic related air pollution and acute hospital admission for respiratory diseases in Drammen, Norway 1995-2000. Eur J Epidemiol 2003; 18 (7): 671-5.

31. Moan J, Dahlback A. The relationship between skin cancers, solar radiation and ozone depletion. Br J Cancer 1992; 65 (6): 916-21.

32. Dotterud LK, Odland JO, Falk ES. Atopic dermatitis and respiratory symptoms in Russian and northern Norwegian school children: a comparison study in two arctic areas and the impact of environmental factors. $J$ Eur Acad Dermatol Venereol 2004; 18 (2): 131-6.

33. Smith-Sivertsen T, Bykov V, Melbye H, Tchachtchine V, Selnes A, Lund E. Sulphur dioxide exposure and lung function in a Norwegian and Russian population living close to a nickel smelter. Int $J$ Circumpolar Health 2001; 60 (3): 342-59.

34. Norseth T. Environmental pollution around nickel smelters in the Kola Peninsula (Russia). Sci Total Environ 1994; 148 (2-3): 103-8.

35. Soyseth V, Kongerud J, Haarr D, Strand O, Bolle R, Boe J. Relation of exposure to airway irritants in infancy to prevalence of bronchial hyper-responsiveness in schoolchildren. Lancet 1995; 345 (8944): 217-20.

36. Lund E, Galanti MR. Incidence of thyroid cancer in Scandinavia following fallout from atomic bomb testing: an analysis of birth cohorts. Cancer Causes Control 1999; 10 (3): 181-7. 